УДК 81

DOI: 10.33184/YVDK-2021-04-30.43

Р.Г. Гатауллин (о.ф.н., проф. БашГУ)

\title{
К ВОПРОСУ О ФУНКЦИЯХ РЕДУПЛИКАЦИИ
}

B cтатье рассматриваются основные функиии редупликации, использование редупликации в "сильныху позищиях текста. Указывается на потенции редупликащии для стилистического варьирования высказывания.

Ключевые слова: периферия словообразования, редупликация, функции редупликация, способы редупликаџии, частотность употребления редупликации.

The main functions of reduplication, the use of reduplication in the "strong" positions of texts are considred in this article. The potential of reduplication for stylistic variation of the statement is indicated.

Key words: periphery of word formation, reduplication, functions of reduplication, methods of reduplication, frequency of use of reduplication.

Вклад периферийных способов словообразования в расширение и обогащение словаря отдельных языков незначителен. Однако как средство стилистического варьирования высказывания в некоторых подъязыках, в художественной и публицистической речи такие деривационные способы довольно активны и употребляются для выражения усилительной, шутливой, иронической, а также многих оттенков пейоративной коннотации.

К периферийным деривационным способам относятся разные виды контаминации, обратное словообразование, редупликации и т.д. Данная статья посвящена анализу некоторых функций редупликации, прежде всего, стилистических, в разных видах текста. При этом под редупликацией понимают «полный или частичный повтор корня, основы или целого слова без или с частичным изменением звукового состава» - „Vollständige oder teilweise Wiederholung der Wurzel, des Stammes oder des ganzen 
Wortes ohne oder mit teilweiser Abänderung des Lautbestandes; wortbildende sekundäre Verdoppelung von Wörtern oder primäre Doppelsetzung von Silben“ [Lewandowski, 1994. - S.856.]. Редупликация как фономорфологическое явление, заключается в повторе отдельных звуков, в удвоении начального слога (частичная редупликация), в повторе основы слова, целого корня (полная редупликация, ср. в английском языке: quack-quack, jugjug, tick-tick, wuff-wuff; в русс. кря-кря, тик-тик) или его части, в результате чего возникает новая лексическая единица. Предельный случай редупликации - повтор, т.е. удвоение всего слова [Виноградов 1990, - с.408], а минимальным видом редупликации является повтор отдельных, как правило, согласных звуков: ср.: русск. вот-вот, еле-еле, чуть-чуть, белыйбелый. Фляйшер/ Барц определяют редупликацию «элементарным способом морфонологической деривации производных слов при помощи звуко-ассоциативного удвоения компонента» „Reduplikation ist eine elementare Art phonologischmorphologischer Erzeugung komplexer Lexeme durch lautassoziative Doppelung“" [Fleischer,W./ Barz 2012, c.94; также: Hentschel,./ Vogel 2009, - c.470; Wiese, 1990, - c. 603-624].

Наличие определенных стилистических функций и значений, как игривой или шутливый оттенок редупликаций позволяет считать этот процесс «экстраграмматическим» [Дресслер, 2000, - с.2-10], ср.: „Und denn gleich an mein Hosenbein, ,hübß aus, Deffen, Süße hübßaus?', ich sie zur Seite, Mann, mir doch egal. Sie aber gleich ,buhu' und heulheul, alte Heulsuse. Ja Pech. Aber Süße jetzt immer so die Fäuste gegen die Augen und , bu-hu' und heulheul, seh ich genau, dazwischen linst die mich an, also die weiß schon alle Tricks. Nä. Und Mama: ,Sososo, Süße', fummelt bisschen an ihren Haaren rum” [Kirsten 2009, - c. 8-9]. „Nützt ihm aber auch nichts, ja Pech, konnte man sich ja denken, die haben ihn schon so im Kreis, nä, eingekesselt, also die silbernen Typen da, und denn zschschsch! zschschsch!, löschen die den aus. Cool. Sind echt Flammenwerfer, die Kanonen, hab ich doch gesagt, der ganze Typ verschmurgelt gerade, Lederklamotten und alles [Kirsten 2009, - c. 10]. Очень емким по содержанию и коннотации является новое слово «шындр-мындр», введенное в обиход тренером Ак Барса Д. Квартальным, ср.: «Ак Барс» уже выпустил мерч. Кто-нибудь знает, что это значит? «Ребята, молодчики! Хорошая игра, боевая 
игра. Ребята, готовимся. Там приезжаем завтра, шиндр-мындр, раскатки не будет - в 14:30 по Москве играем. Спасибо!» - сказал главный тренер «Ак Барса» Дмитрий Квартальнов после победы над «Салаватом Юлаевым» во втором матче полуфинальной серии Восточной конференции Кубка Гагарина. Болельщики в социальных сетях «Ак Барса» сразу начали писать, что готовы покупать футболки с фразой шиндр-мындр. Казанский клуб не растерялся и показал яркий пример ситуативного маркетинга [Квартальнов 2021]. О том, что редупликация является средством привлечения внимания носителей языка, косвенно свидетельствует название недавно появившегося сериала «МурМур» (режиссер - Илья Казанков). Действие картины разворачивается в 1944 году в небольшом городке Муранск. Муранский уголовный розыск местные жители ласково называют «МУР-МУР» [Кино-Театр, 27.04.2021]. Пейоративным значением обладает редупликация санкции-фиганции, ср.: «Вот еще бы двигателя на них отечественные начали делать... MAN, наверное, хороший движок, но опять начнут санкиии-фиганции...,да и стоимость дешевле стала бы» [СПК «Валдай» / https://sdelanounas.ru > blogs, 4.05.2018].

Значительная часть редупликаций опирается на звукоподражания, ср.: „Aber Mama jetzt gleich sauer, ,Quatsch!' Kannst du gar nicht richtig hören, weil, im Fernsehen rattert das jetzt immer so, tack-tack-tack-tack, wetten Maschinenpistole, und denn Schrei, also geil. Und Kuddi gröl-gröl und Süße kichert, also wetten, der kitzel durch“" [Kirsten 2009, - c. 13] „Wie sie da in de Wüste sind, nä, und kein Wasser und nichts, und Onkel Dagobert immer: ,Lechz! Lechz!', und der Schweiß tropft in den Sand, 'oh, ich verschmachte!', aber nee, Tick Trick Track wieder, nä, und die Dukaten finden sie auch“ [Kirsten 2009, - c. 21] ,Wie das Haus in die Luft geflogen ist, wommm!, und der Typ denn über das Auto gesegelt, ssss!, und auf den Boden, chchchchrmmm! Kopf platt, nä, konntest du knirschen hören. Und denn die Kanone raus, dt-dt-dt-dt-dt-dt-dt, und der war hin [Kirsten 2009, - c. 24]

Часто встречаются звукоподражательные слова, напр. ratterknatter, rumsbums, rumsbumsen: „Das Moped ratter knatterte auf den Marktplatz und rumsbumste gegen den Obststand" [Schindler, c.609]. Глагольные редупликации в тексте могут субстантивироваться, rums-bumsen - das Rumbumsen - мн.число: 
die Rumbumsen, cp.: „Diese wenigen Rumsbumsen können niemals das hereinbringen, was sie den Steuerzahlen kosten“ [Millstätter See, 2016]. Как показывают исследования функционирования редупликаций в тексте, их ономатопоэтический характер не исключает семантическую деривацию. „Die Straßen in Los Angeles werden etwas sicherer, weil Promille-Paris in dieser Zeit definitiv nicht fahren (und rums-bumsen) kann" [Wer kann2017]. Своеобразным является звучание редупликаций в современной лирике, сравни, напр. отрывок из стихотворения Вернера Дирка (Werner Dirk):

„Will, also, wissen, wo ihre Wildheiten wohnen,

ihre erogen-revolutionär-explosivsten Zonen...,

wo ist die Schweiz schwül Gewühl und -wimmer

statt rhythmischem Rumsbumsen im Eheschlafzimmer" [Werner 2014, - c.6].

Совершенно по-другому звучит редупликация в учебной литературе по развитию детской речи:

„Auf einem Gummi-Gummi-Berg saß ein Gummi-Gummi-Zwerg.

Der Gummi-Gummi-Zwerg hat eine Gummi-Gummi-Frau.

Die Gummi-Gummi-Frau hat ein Gummi-Gummi-Kind.

Das Gummi-Gummi-Kind hat ein Gummi-Gummi-Kleid.

Das Gummi-Gummi-Kleid hat ein Gummi-Gummi-Loch.

Du bist's doch“" [Elsen 2013, - c. 386].

Узуальное звукоподражательное междометие Schwuppdiwupp со значением быстрого, резкого движения [Duden, c. 1375]; diwupp в этом случае можно отнести к уникальному суффиксу, или Schwuppdiwupp является сложным междометием, состоящим из двух междометий (Schwupp $u$ wupp и соединительного элемента $d i$ ). Имеется многочисленные синонимы, ср.: hopphopp, schwupp, schwupps, holterdiepolter, hopplahopp, husch husch, ratzfatz, rubbel die Katz, rucki zucki, ruckizucki, zappzarapp, zack, zacki, zackzack. Данное междометие относительно активно употребляется (в корпусе более 600 примеров). Сравни стихотворение на употребление «раздражительных» слов в общеупотребительном языке:

Schwuppdiwupp

Schwuppdiwupp

ein hauch

ein schwung 
war doch gestern erst

so jung

noch blütenfrisch

im morgentau

und wie von zauberhand gedreht

plötzlich der wind

heut anders weht

schwuppdiwupp ein warmer schnaufer

dazu der kleine

kurze sprung

dies ist ja wirklich

ganz schön

dumm

[Gedicht 2015].

Элемент(-di-) - кроме выражения идеи связанностей компонентов редупликаций - видимо, выполняет фонетическую функцию: приводит произношение в артикуляционное равновесие. Косвенно об этом свидетельствует появление элемента (-di-) в текстах жанра фольклора. Так, например, в сказке „Aschenputtel“ (Золушка) в обработке братьев Гримм (-di-) употребляется между словами словосочетания в двух вариантах сказки, ср.: Die Tauben entlarven die falschen Schwestern mit den Worten:

„Rucke di guck, rucke $d i$ guck,

Blut ist im Schuck (Schuh):

Der Schuck ist zu klein,

die rechte Braut sitzt noch daheim."

В следующем издании это место звучит иначе: "Sie mussten aber an dem Grabe vorbei, da saßen die zwei Täubchen auf dem Haselbäumchen und riefen: "Rucke di guck, rucke di guck" [Brüder Grimm 1994; Grimms Märchen 2015. - 944].

Кроме нарицательных слов в качестве компонента в структуре редупликации встречаются, правда, относительно редко, и имена собственные. В социальных сетях созданы и использованы игровые слова и контаминации с пейоративной окраской с участием редупликаций имен собственных, сp.: „Ist denn eigentlich irgendjemand in meiner Nähe, mit dem ich fahren könnte? tannimausiliebanguggunddumminnerundeglotz; Klausipausihasi-schatzi? Nimmst mich ab hannover mit?" mal schaun wie das mit 
Mausi is. Klausi, wer hat sich denn angemeldet?" "alles stand schon auf Abbruch, weil die alte Haut von Klausipausi glänzte bis nach China und eine versierte rettende Puderistin war gerade nicht in the Hood [Eine „Gute Nacht Geschichte“ 2015]. Даже на основе подробного анализа случаев функционирования трудно определить конкретное значение данной редупликации. В одном тексте четко выделяется отрицательное значение «тот, кто наступает на демократические права», ср.: „Klausimausi. Nein, jemandem die Meinungsäußerung verbieten müssen "wir" gewiss nicht. Ich tue sogar regelmäßig das Gegenteil und tausche mich mit Bekannten und Freunden aus, die sich dezidiert politisch rechts oder links verorten und nehme das als sehr erhellend und interessant wahr" [taz,de/politik, 15.10.2017]. В других случаях «Klausimausi» означает некий объект обращения, иногда в качестве никнейма, ср.: „Ein junger Macker, mit angeklebten Haaren und langen gelblichen Zähnen, lachte. „Klausimausi, lass das“, sagte die Witwe. Klausimausi, etwas verrückt muss man wohl sein, sich immer wieder auf fremde Kulturen einzulassen. Doch Reisen bildet, und bei meinem [KlausiMausi 2016]. „Klausimausi zog die Lefzen über seine Zahnstängel. »Ick finde det komisch«, sagte er. »Heutzutage wohnt doch niemand mehr in 'ner Laube“" [Lentz 2012].

Основные функции редупликаций с именами собственными - это привлечение внимания читателя; поэтому часто используются в качестве никнеймов в социальных сетях [Гатауллин 2021, с.55-60.], ср. : Achimpachim, Andimandi: «Слушай музыку из библиотеки Andimandi (прослушано 22879 композиций). Создай свой музыкальный профиль на Last.fm крупнейшей в мире» [Andimandi, 2018]. В инстаграме Andimandi Ivanov: Instangram photos; 324 Followers, 1482 Following, 146 Posts - See Instagram photos and videos from Andimandi Ivanov [Andimandi 2018], “andipandi's profile picture. See All Posts From andipandi. More camera effects. More stickers. More ways to message. Only on the app. Switch to the App" [Andimandi 2018]. Andipandi, Annapanna: «Все публикации от автора AnnaPanna на сайте Пикабу - от свежих постов к старым. Подпишитесь на ленту AnnaPanna, если вам [AnnaPanna 2018] «Анна многим известна как AnnaPanna, кондитер и автор кулинарных книг. Информация о странице Anna доступна только авторизованным пользователям. Несмотря на оживленный темп столичной жизни, 
кипящей».. [Как живет рижский кондитер 2020]. Annipanni: "annipanni. ANNA KUNSZENTI · home · contact · postcards. basler postkartenfestival 2014. animals. drawings and paintings. zentangles. ink drawings. Others". [AnniPanni// www.annipanni.com].

Annipanni содержится в названии иллюстрированной книги для детей венгерского автора [Marék 2009, - с36] "The script was made of the following books: Boribon és Annipanni, Good night, Annipanni! Boribon's Birthday, Boribon is Ill, The house of Boribon and Annipanni, tell me a story!". "The relationship between Boribon and Annipanni is a nice mixture of friendship, and bond between a mother and a child" [Marék 2009, - c36]. [Binemine употребляется в качестве имени пользователя Instagram Facebook "Better-Go-Now member page for BInemine". [Binemine 2015]. Кроме никнейма Binemine встречается как обозначение химического соединения, ср.: “синтез на основе BinePine". Binepine: "We are not allowed to display external PDFs yet. You will be redirected to the full text document in the repository in a few seconds" [Schröder-Holzhacker 2017]. Никнеймом является также Danimani: «Посмотрите, что нашел пользователь Dani Mani Pinterest - самой большой в мире коллекции идей. [Dani Mani (danimani121211) на Pinterest// www.pinterest.com > danimani121211. www.ricardo.ch > shop > ratings] В текстах СМИ Danipani употребляется в качестве топонима - названия деревни. «Danimani.sk» на Facebook» www.facebook.com > danimani

Продукты редупликации относятся к более непринужденному стилю языка. Анализ данных корпусов современного немецкого языка Института немецкого языка (Deutsches Referenzkorpus) и архива корпусов письменного немецкого языка (COSMAS II) указывает на значительную активность в употреблении редупликаций; от 70 до 6700: Schnippchnapp (70), Ticktack (100), Schickimicki (400), Krimskrams (980), Zickzack (1150), Mischmasch (2100), Singsang (2700), Hickhack (5150), Wirrwarr (6700). В исследованиях отмечаются функции ономатопоэтического выражения, интенсивно-квалитативная функция, интенсивно-итеративная функции. 


\section{ЛИТЕРАТУРА}

1. Виноградов В.А.: Редупликация. // Лингвистический энциклопедический словарь. Москва «Советская энциклопедия» 1990. - 686c.

2. Гатауллин Р.Г. Образование никнеймов при помощи редупликации. / Доклады Башкирского университета 2021. Том 6,№ 1. - c.55-60.

3. Как живет рижский кондитер. Дом и сад > Квартира и дом, rus.delfi.lv > 24.09.2020

4. Квартальнов Дмитрий родил мем шиндр-мындр. https://sport.business-gazeta.ru > article 21.03.2021

5. Кино-Театр.PУ https://www.kino-teatr.ru/kino/, 27.04.2021

6. Andimandi www.last.fm > user >, 24.03.2018

7. Andimandi @andimandiivanov //www.instagram.com > andima... 24.03.2018

8. AnnaPanna - Bce посты пользователя pikabu.ru > 12.06.2018 @ AnnaPanna

9. Binemine member // better-go-now.com > members > BInemine, 12.02.2015; https://www.facebook.com/ BineMine

10. Danimani.sk» на Facebook» www.facebook.com $>$ danimani

11. Dressler, Wolfgang U. 'Extragrammatical vs. Marginal Morphology'. In Ursula Doleschal and Anna M. Thornton (eds.) Extragrammatical and Marginal Morphology. (Lincom Studies in Theoretical Linguistics 12). München: Lincom Europa, 2000 c. $2-10$

12. Duden Deutsches Universal Wörterbuch A - Z. Dudenverlag: Mannheim/ Wien/Zürich, 1989. - 1816c.

13. Eine „Gute Nacht Geschichte“ www.facebook.com〉 notes 13.07.2015

14. Elsen, Hilke: Erstspracherwerb: Der Erwerb des deutschen Lautsystems. Springer-Verlag 2013. - 406c.

15. Fleischer,W., Barz, I. Wortbildung der deutschen Gegenwartssprache. 4., völlig neu bearbeitete Auflage. Berli/ Boston, De Gruyterc 2012. - 484 Seiten. C.94;

16. Grimm, Jacob und Wilhelm: Kinder- und Hausmärchen. Durchgesehene und bibliographisch ergänzte Ausgabe, ReclamVerlag Stuttgart 1994. 
17. Grimm, Jacob und Wilhelm: Grimms Märchen - vollständig und illustriert Kinder- und Hausmärchen. Anaconda Verlag - 2015. 944Seiten

18. Gedicht: Schwuppdiwupp // www.reimemaschine.de> sons.3.06.2015

19. Hentschel, E./ Vogel, M.P.: Deutsche Morphologie. - (De Gruyter Lexikon) Berlin, New York, 2009. - 479S. - c.470;

20. Kirsten Boie: Ich ganz cool. Verlag Friedrich Oetinger, Hamburg 2009. - 111 Seiten.

21. KlausiMausi Römisch-Katholische Kirche Anzing // www.himmlisch-plaudern.at> 26.10.2016.

22. Lentz, Georg: Weiße mit Schuss. Edel Elements, 2012. - 336c. books.google.ru > books

23. Lewandowski, Th. Linguistisches Wörterbuch. Bd.2 Quelle\&Mezer; Heidelberg, Wiesbaden 1994. - 882 стр.

24. Marék Veronika: «Boribon and Annipanni». Из-во Cantamilla LLC; 2009. - 36c. Books of Marék Veronika are available at the Pagony Bookstore

25. Marék Veronika: Boribon and Annipanni// budapestbabszinhaz.hu > bori

26. Millstätter See: Förderung bringt. // www.kleinezeitung.at〉 kaernten 15.07.2016

27. Schindler Wolfgang: Reduplizierende Wortbildung im Deutschen Zeitschrift für Phonetik, Sprachwissenschaft und. Kommunikationsforschung (ZPSK), Berlin 44 (1991) 5, 597-613

28. Schröder-Holzhacker, Christian: Synthesis and reactivity of BINEPINE-based chiral Fe(II) PNPpincer complexes // core.ac.uk > download > pdf

29. taz,de/politik, 15.10.2017

30. Wer kann Paris-Hilton helfen? // www.wallstreet-online.de > Foren > Stars \& Sternchen, 17.05. 2019

31. Werner, Dirk: Voll unsittlicher Absicht. Lyrik, Prosa, Limericks. Esslingen 2014. - 116S. c.6// www.civ-buch.de > leseproben

32. Wiese, R.: Über die Interaktion von Morphologie und Phonologie - Reduplikation im Deutschen. //ZPSK 43, 1990. - c. 603-624

(C) Гатауллин Р.Г., 2021 г. 